\title{
HUBUNGAN ANTARA SANITASI KAPAL DAN PERILAKU ANAK BUAH KAPAL DENGAN KEBERADAAN TIKUS PADA KAPAL YANG BERSANDAR DI WILAYAH KERJA KANTOR KESEHATAN PELABUHAN KELAS I SURABAYA TAHUN 2017
}

\author{
GITA ARUMSARI *), ARIF WIDYANTO **), ASEP TATA GUNAWAN**) \\ Jurusan Kesehatan Lingkungan Politeknik Kesehatan Kemenkes Semarang, \\ Jl. Raya Baturaden KM 12 Purwokerto, Indonesia
}

\begin{abstract}
Abstrak
XVI+104 halaman : tabel, gambar,lampiran

Sanitasi kapal merupakan segala usaha yang ditujukan terhadap faktor lingkungan di kapal untuk memutuskan mata rantai penularan penyakit guna memelihara dan mempertinggi derajat kesehatan. Keberadaan vektor dan binatang pengganggu di atas kapal dapat mempengaruhi kondisi kesehatan masyarakat pelabuhan pada khususnya dan masyarakat lain yang berada diluar pelabuhan pada suatu wilayah tersebut, karena vektor dan binatang pengganggu dapat menularkan penyakit kepada manusia. Tujuan penelitian mengetahui hubungan sanitasi kapal dan perilaku anak buah kapal pada kapal yang bersandar di wilayah kerja Kantor Kesehatan Pelabuhan Kelas I SurabayaJenis penelitian yang digunakan observasional dengan pendekatan crossectional. Penelitian ini dilakukan untuk mengetahui hubungan sanitasi kapal dan perilaku anak buah kapal dengan keberadaan tikus. Sampel penelitian ini 37 kapal dalam negeri yang memperpanjang Ship Sanitation Control Exemption Certificate (SSCEC) . Hasil penelitian menggunakan uji chi-Square dengan Fisher Exact $\rho=0,000$ $(\rho<\alpha)$ yang artinya Ho ditolak dan Ha diterima yang artinya ada hubungan sanitasi kapal dan perilaku anak buah kapal dengan keberadaan tikus di kapal yang bersandar di wilayah kerja Kantor Kesehatan Pelabuhan Kelas I Surabaya. Kesimpulan penelitian ini adalah hubungan sanitasi kapal dan perilaku anak buah kapal dengan keberadaan tikus, disarankan bagi perusahaan pemilik kapal untuk memperbaiki memperhatikan sanitasi kapal dan perilaku anak buah kapal agar kapal tidak mempunyai faktor risiko untuk mengundang keberadaan tikus di kapal.
\end{abstract}

Daftar bacaan : 23 (1967-2015)

Kata Kunci : Sanitasi Kapal, Perilaku Anak Buah Kapal, Keberadaan Tikus

Klasifikasi : -

\begin{abstract}
XV+104 pages: table,picture,attachment

Sanitation ship is an attempt to break the chain of transmission of the disease to maintain and improve health. The presence of vectors and abusive animals on board can affect the public health conditions of ports in particular and other communities outside the harbor in a given area, since vectors and pests can transmit disease to humans. The purpose of this research is to know the relation of ship sanitation and ship crew behavior on ship which lean in work area of Health Office of Class I Port of Surabaya. This type of research used observasional with crossectional approach. This research was conducted to find out the relation of ship sanitation and ship crew behavior in the presence of rats. The sample of this study is 37 domestic ships that extend SSCEC. The result of this research is chi-square test with Fisher Exact $\rho=0,000(\rho<\alpha)$ which means Ho refused to show there is relation of ship sanitation and ship's behavior with the existence of mouse in ship.The conclusion of research is relation between ship's sanitation and ship's behavior with the presence of rats, it is suggested for the ship owner company to improve attention to the sanitation of the ship and the behavior of the crew so that the ship does not have any risk factor to invite the presence of rats on board.

Reference : 23 (1967-2015)

Keywords : Sanitation Ship, Crew Behavior, Mouse

Classification : -

*gitaarumsari25@gmail.com

**arifwidyanto74@yahoo.com

***aseptatagunawan@yahoo.com
\end{abstract}




\section{Pendahuluan}

Menurut H.L. Blum, dikutip Notoadmodjo (2007), derajat kesehatan dipengaruhi 4 (empat) macam faktor yaitu lingkungan, perilaku, pelayanan kesehatan, dan keturunan . Faktor lingkungan dan perilaku merupakan faktor terbesar yang berpengaruh terhadap tinggi rendahnya derajat kesehatan.Oleh karena itu, lingkungan sehat dan perilaku sehat perlu diupayakan dengan sungguh-sungguh.

Sarana transportasi yang dianggap sebagai lingkungan tempat tinggal sementara yang memiliki waktu menetap relatif lama adalah kapal laut. Sesuai dengan keadaan tersebut, serta amanat Undang-Undang Nomor 1 Tahun 1962 tentang Karantina Laut, maka sanitasi di kapal merupakan salah satu faktor yang sangat penting dalam mendukung pengawasan kesehatan khususnya manusia di dalamnya maupun masyarakat pada umumnya. Menurut Permenkes No. 530/Menkes/Per/VII/1987, sanitasi kapal merupakan segala usaha yang ditujukan terhadap faktor lingkungan di kapal untuk memutuskan mata rantai penularan penyakit guna memelihara dan mempertinggi derajat kesehatan. Menurut Permenkes 82 Tahun 2014 bahwa Penanggulangan Penyakit Menular adalah upaya kesehatan yang mengutamakan aspek promotif dan preventif yang ditujukan untuk menurunkan dan menghilangkan angka kesakitan, kecacatan, dan kematian, membatasi penularan, serta penyebaran penyakit agar tidak meluas antardaerahmaupun antarnegara serta berpotensi menimbulkan kejadian luar biasa/wabah. Menurut Keputusan Menteri Kesehtan Repunlik Indonesia No 431 Tahun 2007 pengendalian resiko lingkungan pada alat angkut sangat dibutuhkan guna mengurangi risiko penularan penyakit secara global.

Pada saat ini pelabuhan tidak hanya berfungsi sebagai pintu keluar masuk barang, lebih dari itu sudah merupakan sebagai sentra industri, pusat perdagangan dan pariwisata yang banyak menyerap tenaga kerja. . Mobilisasi yang tinggi dari aktivitas di pelabuhan, secara otomatis penyebaran penyakit akan semakin cepat dan beragam, sehingga akan berpotensi menimbulkan dampak yang merugikan bagi pencapaian. Peraturan Perundang Undangan Kesehatan Nasional dan Internasional Health Regulation (IHR) tahun 2005, semua alat angkut harus bebas dari vektor maka pemeriksaan kesehatan di kapal mutlak diperlukan, mengingat kapal dapat membawa vektor penyakitDunia (WHO) mengantisipasi untuk terjadinya penyakit yang menimbulkan masalah kedaruratan kesehatan yang meresahkan dunia Public Health Emergency of International Concern (PHEIC) dengan membentuk International Health Regulation (IHR) yang berlaku bagi seluruh negara, dimana setiap negara wajib melindungi rakyatnya dengan mencegah terjadinya penyakit yang masuk dan keluar dari negaranya.

Peningkatan sanitasi kapal menurut permenkes No. 530/Menkes/Per/VII/1987 yaitu meniadakan / menghilangkan sumber penularan penyakit di dalam kapal Agar kapal tetap bersih pada waktu berangkat maupun sedang berlayar yang bertujuan untuk kesejahteraan penumpang.Penumpang dan Anak Buah Kapal (ABK) agar tidak terkena penyakit menular yang di dapatkan di kapal yang ditumpanginya.Institusi yang memiliki kewenangan untuk melakukan pemeriksaan yaitu Kantor Kesehatan Pelabuhan (KKP). Menurut Permenkes No.356/Menkes/IV/2008, bahwa KKP mempunyai tugas melaksanakan pencegahan masuk dan keluarnya penyakit karantina dan penyakit menular potensial wabah, kekarantinaan, pelayanan kesehatan terbatas di wilayah kerja Pelabuhan / Bandara dan Lintas Batas, serta pengendalian dampak kesehatan lingkungan. Upaya sanitasi kapal merupakan tanggung jawab pemilik kapal melalui nakhoda kapal dan anak buah kapal. ABK bertanggung jawab terhadap kebersihan kapal dan sarana lainnya yang mendukung sanitasi kapal.Peningkatan sanitasi kapal adalah usaha merubah keadaan lingkungan alat angkut yang dapat berlayar menjadi lebih baik sebagai usaha pencegahan penyakit dengan memutuskan mata rantai penularan penyakit.

Kantor Kesehatan Pelabuhan KelasI Surabaya, merupakan salah satu unit pelaksana teknis yang melakukan tugas pengawasan alat angkut terhadap kapal yang datang dari luar negeri dan dari daerah terjangkit. Pelabuhan laut Surabaya sebagai salah satu pintu masuk dari bagian Selatan Surabaya Daratan banyak disinggahi oleh kapalkapal yang datang dari luar negeri yang berasal dari dalam negeri maupun luar negeri. Maka terhadap kedatangan kapal tersebut dilakukan tindakan pengawasan kesehatan kapal, salah satunya adalah mengamati keberadaan vektor di atas kapal dengan melakukan observasi pada bagian bagian/kompartemen kapal yang ada, termasuk muatan kapal. Hal ini dilakukan sebagai upaya sistem kewaspadaan dini mengantisipasi terjadinya penularan penyakit yang disebabkan oleh faktor risiko yang terdapat di kapal tersebut. Upaya pengendalian risiko lingkungan bertujuan untuk membuat wilayah pelabuhan laut dan alat angkut tidak menjadi sumber penularan ataupun habitat yang subur bagi perkembang biakan kuman/vektor penyakit (Ditjen PP-PL 2007).

Keberadaan vektor dan binatang pengganggu di atas kapal dapat mempengaruhi kondisi kesehatan masyarakat pelabuhan pada khususnya dan masyarakat lain yang berada diluar 
pelabuhan pada suatu wilayah tersebut, karena vektor dan binatang pengganggu dapat menularkan penyakit kepada manusia. Tikus dapat membahayakan manusia karena mampu menularkan penyakit pada manusia. Tikus mampu menularkan penyakit pada manusia dengan membawa benih penyakit, pinjal, kutu, bakteri dan parasit. Binatang dari suku Murides ini dikenal sebagai sumber beberapa penyakit zoonosis. Beberapa jenis penyakit yang ditularkan oleh tikus antara lain Pes/Plaque, Leptospirosis, Scub Typhus, Murine Thypus, Rat Bite Fever, Salmonellosis, Lymphatic Chorionmeningitis, Hantavirus Pulmonary Syndrome dan Lassa Fever. Penyakitpenyakit tersebut ditularkan tikus melalui cara bervariasi mulai dari gigitan tikus, kencing tikus, kotoran tikus, maupun yang ditularkan secara tak langsung melalui hewan lain yang tertular penyakit dari tikus maupun makanan/minuman, air, atau benda yang terkontaminasi.

Keberadaan vektor penyakit dikapal selain disebabkan oleh faktor- faktor fisik di kapal yaitu ruangan/kompartemen kapal, juga tidak terlepas dari tindakan anak buah kapal (ABK), demikian juga setiap kapal yang bersandar, pada tali kapal tidak dipasang perisai tikus, penerangan pada ruangan/kompartemen kapal sering tidak menyala. Hal ini dapat menyebabkan berkembang biaknya vektor pada ruangan/ kompartemen kapal yang merupakan faktor risiko terjadinya sumber dan penularan penyakit. Data kedatangan kapal pada Kantor Kesehatan Pelabuhan Surabaya tahun 2016 sebanyak 2.457 kapal, dimana keberadaan vektor penyakit sebanyak 33 kapal dari seluruh kedatangan kapal yang singgah dan bersandar dipelabuhan wilayah kerja KKP Kelas I Surabaya. (KKP I Surabaya, 2016 ). jenis tikus yang tertangkap yaitu ratus tanezumi, ratus norvegicus, ratus diardi dan suncus murinus dan jenis pinjal yang teridentifikasi adalah xenopshylla cheophis dan xenopshsylla astia dengan angka indeks pinjal dan didapatkan angka indeks pinjal di semua wilayah kerja KKP tidak melebihi ketentuan yaitu lebih besar dari 2. Selama tahun 2016 seluruh kapal yang telah diawasi sebanyak 2.457 kapal. Hasil pemeriksaan tanda - tanda kehidupan tikus di 2.457 kapal, diketahui ada 33 kapal yang ditemukan tanda - tanda kehidupan tikus..

Berdasarkan latar belakang tersebut, penulis ingin meneliti hubungan antara sanitasi kapal dan waktu sandar kapal yang memengaruhi keberadaan tikus di kapal sehingga dapat dirumuskan strategi kebijakan manajemen pengendalian vektor penular penyakit di kapal, sehingga peneliti tertarik untuk meneliti"Hubungan Sanitasi Kapal Dan Perilaku Anak Buah Kapal Dengan Keberadaan Tikus Pada Kapal Yang Bersandar Di Wilayah Kerja KKP Kelas I Surabaya Tahun 2017 “.
Tujuan Penelitian ini adalah untuk

a. Memeriksa keberadaan tikus pada kapal yang bersandar di wilayah pelabuhan Tanjung Perak KKP Kelas I Surabaya

b. Mendeskripsikan sanitasi kapal di wilayah pelabuhan Tanjung Perak KKP Kelas I Surabaya.

c. Mendeskripsikan perilaku anak buah kapal di wilayah pelabuhan Tanjung Perak KKP Kelas I Surabaya.

d. Menganalisis hubungan antara sanitasi kapal dengan keberadaan tikus pada kapal yang bersandar di wilayah pelabuhan Tanjung Perak KKP Kelas I Surabaya

e. Menganalisis hubungan antara perilaku anak buah kapal dengan keberadaan tikus pada kapal yang bersandar di wilayah pelabuhan Tanjung Perak KKP Kelas I Surabaya.

\section{Bahan dan Metode}

Jenis penelitian yang digunakan adalah penelitian observasional dengan metode analitik. Penelitian ini menggunakan pendekatan cross sectional. Pada kapal yang bersandar di Pelabuhan Tanjung Perak Surabaya kemudian observasi sanitasi kapal menggunakan cheklist dan wawancara menggunakan kuisioner pada Anak Buah Kapal

Besar sampel berdasarkan rumus cross sectional pada populasi rata - rata kapal per bulan tahun 2016 yaitu 132 kapal didapatkan sampel yang berjumlah 37 kapal . Bedasarkan pertimbangan teknis dilapangan dan pintu masuk pelabuhan peneliti melakukan pemeriksaan terhadap kapal 3 kapal per hari.

Kriteria inklusi dalam penelitian ini yaitu

1) Kapal dalam negeri (Republik Indonesia)

2) Kapal yang memperpanjang Ship Sanitaton Control Exemption Certificate (SSCEC)

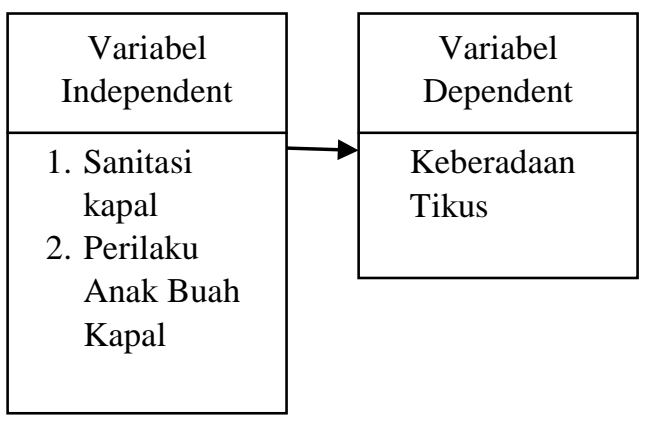

Gambar 3.1 : Struktur Hubungan Variabel 


\section{Hasil dan Pembahasan}

\section{A. Gambaran Umum Kantor}

\section{KesehatanPelabuhan Kelas I Surabaya}

1.Tugas pokok dan Fungsi

a. Tugas Pokok

Tugas pokok KKP bedasarkan Peraturan Menteri Kesehatan Republik Indonesia Nomor 2348/MENKES/PER/XI/2011

tentang perubahan atas peraturan Menteri Kesehatan Nomor : 356/MENKES/PER/IV/2008 tentang Organisasi dan Tata Kerja Kantor Kesehatan Pelabuhan Bab I Pasal 2 adalah melaksanakan pencegahan masuk dan keluarnya penyakit, penyakit potensial wabah,surveilans epidemiologi, kekarantinaan ,pengendalian dampak kesehatan lingkungan pelayanan kesehatan, pengawasan OMKABA serta pengamatan terhadap penyakit baru dan penyakit yang muncul kembali, bioterorisme, unsur biologi, kimia, dan pengamanan radiasi di wilayah bandara, pelabuhan, dan lintas batas negara.

b. Fungsi

Dalam melaksanakan tugas KKP menyelegarakan fungsi :

1) Pelakasanaan kekarantinaan

2) Pelaksanaan pelayanan kesehatan

3) Pelaksanaan pengendalian resiko lingkungan di bandara, pelabuhan dan lintas batas darat negara.

4) Pelaksanaan pengamatan penyakit, penyakit potensial wabah penyakit baru, dan penyakit yang muncul kembali.

5) Pelakasanaan pengamanan radiasi pengion dan non pengion , biologi, dan kimia.

6) Pelaksanaan sentra/simpul jejaring surveilans epidomiologi sesuai penyakit yang berkaitan dengan lalu lintas nasional, regional, dan internasional.

7) Pelaksanaan, fasilitasi dan advokasi kesiapsiagaan dan penanggulangan Kejadian Luar Biasa (KLB) dan bencana di bidang kesehatan, serta matra termasuk penyeleggaraan kesehatan haji dan perpindahan penduduk.
8) Pelaksanaan, fasilitasi dan advokasi kesehatan kerja di lingkungan bandara, pelabuhan, dan lintas batas darat negara.

9) Pelaksanaan pengawasan kesehatan alat angkut dan muatannya.

10) Pelaksanaan pemberian pelayaran kesehatan kerja bandara, pelabuhan dan lintas batas darat negara.

11) Pelaksanaan jejaring informasi dan teknologi di bidang kesehatan bandara, pelabuhan, dan lintas batas darat negara.

12) Pelaksanana jejaring kerja dan kemitraan bidang kesehatan bandara pelabuhan, dan lintas batas darat negara.

13) Pelaksanaan kajian kekarantinaan, pengendalian resiko lingkungan, dan surveilans kesehatan pelabuhan.

14) Pelaksanaan pelatihan teknis di bidang kesehatan bandara,pelabuahan,dan lintas batas darat negara.

15) Pelaksanaan ketatausahaan dan kerumahtanggan KKP.

c. Kantor Kesehatan Pelabuhan Kelas I Surabaya terdiri dari:

1) Bagian Tata Usaha

Bagian tata usaha mempunyai tugas melaksanakan koordinasi dan penyusunan program, pengelolaan informasi, evaluasi, pelaporan, urusan tata usaha, keuangan, penyelenggaraan pelatihan, kepegawaian, serta perlengkapan dan rumah tangga. Dalam melaksanakan tugas bagian tata usaha menyelenggarakan fungsi :

a. Pelaksanaan koordinasi dan penyusunan program serta pelaporan

b. Pelaksanaan urusan keuangan

c. Pelaksanaan urusan kepegawaian

d. Pelaksanaan urusan umum

e. Koordinasi penyiapan pelatihan

2) Bagian Bidang Pengendalian Karantina dan Surveilans Epidemiologi

Bidang pengendalian karantina dan surveilans epidemiologi 
mempunyai tugas melaksanakan perencanaan dan evaluasi serta penyusunan laporan dibidang kekarantinaan, surveilans epidemiologi penyakit dan penyakit potensial wabah dan muatannya, lalu lintas OMKABA ekspor dan impor serta pengembangan teknologi, pendidikan dan pelatihan bidang kekarantinaan di wilayah kerja bandara, pelabuhan, dan lintas batas darat negara. Dalam melaksanakan tugas tersebut Bidang Pengendalian Karantina dan Surveilans Epidemiologi mempunyai fungsi :

a. Kekarantinaan surveilans epidemiologi penyakit dan penyakit potensial wabah

b. Kesiapsiagaan, pengkajian, serta advokasi penanggulangan KLB dan bencana/pasca bencana bidang kesehatan.

c. Pengawasan lalu lintas OMKABA ekspor dan impor serta alat angkut, termasuk muatannya.

d. Kajian dan diseminasi informasi kekarantinaan di wilayah kerja bandara, pelabuhan, dan lintas batas darat negara.

e. Pendidikan dan pelatihan bidang kekarantinaan.

f. Pelaksanaan jejaring kerja dan kemitraan bidang kekarantinaan.

g. Pelaksanaan pengembangan teknologi bidang kekarantinaan di wilayah kerja bandara, pelabuhan, dan lintas batas darat negara.

h. Penyusunan laporan bidang pengendalian karantina dan surveilans epidemiologi.

3) Bidang Pengendalian Risiko Lingkungan

Bidang penegendalian risiko lingkungan mempunyai tugas melaksanakan perencanaan, pemantauan, dan evaluasi, penyusunan laporan di bidang pengendalian vektor dan binatang penular penyakit, pembinaan sanitasi lingkungan, jejaring kerja, kemitraan, kajian dan pengembangan teknologi, serta pendidikan dan pelatihan bidang pengendalian risiko lingkungan di wilayah kerja bandara, pelabuhan, dan lintas batas darat negara. Dalam melaksanakan tugas Bidang Pengendalian Risiko Lingkungan menyelenggarakan fungsi :

a. Pengawasan penyediaan air bersih, serta pengamanan makanan dan minuman.

b. Hygiene dan sanitasi lingkungan gedung/bangunan.

c. Pengawasan pencemaran udara, air dan tanah.

d. Pemeriksaan dan pengawasan higiene dan sanitasi kapal/pesawa/alat transportasi lainnya di lingkungan bandara, pelabuhan, dan lintas batas darat negara.

e. Pemberantasan serangga penular penyakit, tikus dan pinjal di lingkungan bandara, pelabuhan, dan lintas batas darat negara.

f. Kajian dan pengembangan teknologi di bidang pengendalian risiko lingkungan bandara, pelabuhan, dan lintas batas darat negara.

g. Pendidikan dan pelatihan bidang pengendalian risiko lingkungan bandara, pelabuhan, dan lintas batas darat negara.

h. Pelaksanaan jejaring kerja dan kemitraan dibidang pengendalian risiko lingkungan bandara, pelabuhan, dan lintas batas darat negara.

i. Penyusunan laporan dibidang pengendalian risiko lingkungan.

4) Bidang Upaya Kesetan dan Lintas Wilayah

Bidang Upaya Kesehatan dan Lintas Wilayah Mempunyaimempunyai tugas melaksanakan perencanaan, pemantauan, dan evaluasi, penyusunan laporan di bidang pelayanan kesehatan terbatas, kesehatan haji, kesehatan kerja, 
kemitraan, kajian dan teknologi, serta pendidikan dan pelatihan bidang upaya kesehatan pelabuhan di wilayah kerja bandara, pelabuhan, dan lintas batas darat negara.

d. Wilayah Kerja

1) Wilayah kerja KKP merupakan unit kerja fungsional di lingkungan

bandara,pelabuhan,dan lintas batas darat negara, yang berada di bawah dan bertanggungjawab kepada kepala KKP.

2) Wilayah kerja dipimpin oleh seorang koodinator yang ditetapkan oleh kepala KKP.

3) Dalam melaksanakan tugasnya,koordinator dibantu oleh kelompok jabatan fungsional dalam jabatan nonstruktural.

4) Perubahan wilker ditetapkan oleh Menteri Kesehatan.

e. Penerbitan Ship Sanitation Control Certificate Exemption Certificate(SSCEC)

SSCEC adalah dokumen kesehatan yang diberikan kepada alat angkut kapal yang setelah dilakukan pemeriksaan kapal tim Kantor Kesehatan Pelabuhan Kelas I Surabaya dan dinyatakan bebas dari tanda tanda kehidupan tikus. SSCEC berlaku selama 6 bulan. Jika dalam pemeriksaan terdapat tanda - tanda tikus maka diterbitkan SSCC dan dilakukan tindakan pengendalian oleh Kantor Kesehatan Pelabuhan Kelas I Surabaya.

Langkah - langkah penerbitan SSCEC/SSCC

1) Agen pelayaran membuat surat permohonan penerbitan SSCEC kepada Kepala Kantor Kesehatan Pelabuhan Kelas I Surabaya.

2) Kepala kantor Kesehatan Pelabuhan mendidposisikan permohonan tersebut kepada Kepala Seksi Pengendalian Karantina dan Surveilens Epidemiologi (Untuk menerbitkan SSCEC) dan Kepala Seksi Pengendalian Risiko Lingkungan (Untuk pemeriksaan kapal dalam rangka penerbitan SSCEC)

3) Kepala Seksi Pengendalian Risiko Lingkungan melaporkan hasil pemeriksaan kepada kepala Kantor Kesehatan Pelabuhan Kelas I Surabaya.

4) Agent pelayaran melakukan penyelesaian pembayaran.

5) Petugas Kantor Kesehatan Pelabuhan Kelas I Surabaya meregistrasi SSCEC/SSCC registrasi penerbitan SSCEC/SSCC. Yang akan dikeluarkan ke dalam buku registrasi penerbitan SSCEC/SSCC

6) Petugas Kantor Kesehatan Pelabuhan Kelas I Surabaya menyerahkan Sertifikat kepada Agen pelayaran

\section{B. Data Umum}

1. Jenis Kapal

Tabel 4.1 : Jenis Kapal

\begin{tabular}{cccc}
\hline Variabel & Kategori & Jumlah & $\%$ \\
\hline Jenis & Penumpang & 12 & $32,5 \%$ \\
\cline { 2 - 4 } Kapal & Barang & 25 & $67,5 \%$ \\
\cline { 2 - 4 } & Jumlah & 37 & $100 \%$ \\
\hline
\end{tabular}

Bedasarkan penelitian yang telah dilaksanakan didapatkan hasil jenis kapal barang lebih banyak bersandar dengan jumlah 25 kapal yang mempunyai presentasi sebesar $67,5 \%$ dan kapal penumpang sebanyak 12 kapal dengan persentase sebesar 32,5\%.

Variabel Kategori Jumlah \%

\begin{tabular}{llcc}
\hline Jumlah & $<25$ orang & 28 & $75,6 \%$ \\
ABK & & & \\
\cline { 2 - 4 } $\mathrm{m}$ & $>25$ orang & 9 & $24,4 \%$ \\
$\mathrm{l}$ & & 37 & $100 \%$ \\
$\mathrm{nyyy}$ & Jumlah & & \\
$\mathrm{h}$ & & &
\end{tabular}

Anak Buah Kapal

Tabel 4.2 : Jumlah Anak Buah Kapal

Bedasarkan penelitian jumlah kapal yang memiliki anak buah kapal < 25 orang sebanyak 28 kapal dengan 


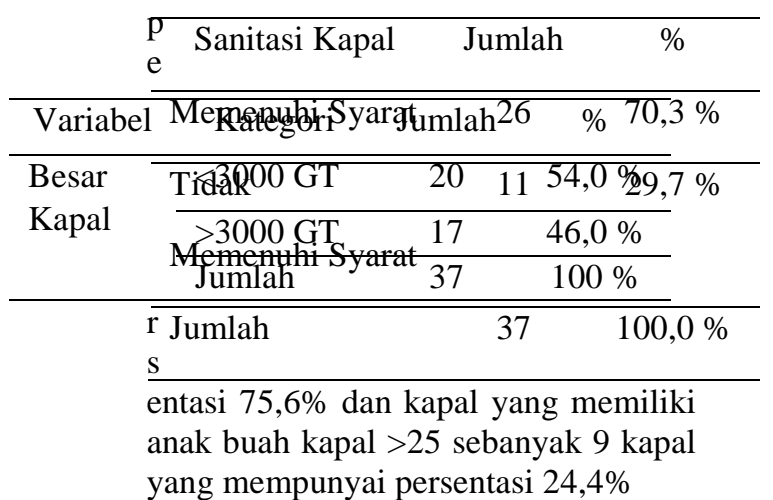

3. Besar kapal

Tabel 4.3 : Besar Kapal

\begin{abstract}
Bedasarkan penelitian yang telah dilaksanakan didapatkan hasil kapal yang memiliki besar < 3000 GT sebanyak 20 kapal dengan persentase 54,0 \% dan kapal yang memiliki besar > 3000 GT sebanyak 17 dengan persentase $46,0 \%$
\end{abstract}

\section{Data Khusus}

\section{Hasil univariat}

Kapal dalam penelitian ini adalah kapal dalam negeri dan kapal yang memperpanjang Ship Sanitation Control Certificate (SSCEC) di wilayah kerja Kantor Kesehatan Pelabuhan Kelas I Surabaya pada bulan 2 April 2017 - 20 April 2017 yang berjumlah 37 kapal.

a. Sanitasi Kapal Sanitasi kapal pada kapal yang bersandar di wilayah kerja Kantor Kesehatan Pelabuhan Kelas I Surabaya pada tahun 2017

Berikut merupakan hasil pemeriksaan sanitasi kapal pada 37 kapal yang bersandar di wilayah pelabuhan tanjung perak surabaya :

Tabel 4.4 : Sanitasi Kapal
$\mathrm{Ka}$

Kapal yang memiliki kondisi sanitasi kapal yang memenuhi syarat sebanyak 26 kapal dengan persentase 70,3 \% dan kapal yang meiliki kondisi sanitasi yang tidak memenuhi syarat sebanyak 11 kapal dengan persentase 29,7 \% . Hal ini menunjukkan > $50 \%$ kapal yang diperiksa memiliki kondisi sanitasi kapal yang memenuhi syarat. akan tetapi, kapal yang telah memenuhi syarat tidak sepenuhnya bebas dari risiko di temukan tanda - tanda keberadaan tikus dan keberadaan tikus. Masih didapatkan ruang ruang yang belum memenuhi persyaratan sanitasi kapal dan berpotensi mengundang tikus yang dapat menjadi sumber makanan dan tempat perkembangbiakan tikus.

b. Perilaku Anak Buah kapal pada kapal yang bersandar di wilayah kerja Kantor Kesehatan Pelabuhan Kelas I Surabaya pada tahun 2017

Berikut merupakan hasil wawancara kepada 37 orang anak buah kapal pada kapal yang bersandar di wilayah pelabuhan tanjung perak surabaya :

Tabel 4.5

\begin{tabular}{llc}
\hline \multirow{2}{*}{ Perilaku ABK $:$ Jumlah } & $\%$ \\
& P & \\
\hline Baik & e 28 & $75,6 \%$ \\
& r & \\
\hline Tidak baik & i 9 & $24,4 \%$ \\
& l & \\
\hline Jumlah & a 37 & $100,0 \%$ \\
& k & \\
& u Anak Buah Kapal
\end{tabular}

Kapal yang memiliki anak buah kapal berperilaku baik sebanyak 28 orang dengan persentase $75,6 \%$ dan anak buah kapal yang memiliki perilaku tidak baik sebanyak 9 orang dengan persentase 24,4 \%. Hal ini menunjukkan bahwa kapal yang memiliki anak buah kapal dengan perilaku baik > 50 \% kepada anak buah kapal yang telah di wawancara. 
Akan tetapi, perilaku anak buah kapal yang dalam kategori baik tidak sepenuhnya tidak berisiko mengundang keberadaan tikus dikarenakan masih banyak perilaku anak buah kapal yang kurang peduli

\begin{tabular}{|c|c|c|c|c|}
\hline \multirow{3}{*}{$\begin{array}{c}\text { Perilaku } \\
\text { ABK }\end{array}$} & \multicolumn{2}{|c|}{ Keberadaan Tikus di Kapal } & \multirow[b]{2}{*}{$\begin{array}{l}\text { Jumlah } \\
\left(\sum\right)\end{array}$} & \multirow{3}{*}{$\begin{array}{c}\text { Nilai } \\
\text { P }\end{array}$} \\
\hline & $\begin{array}{c}\text { Tidak } \\
\text { Terdapat } \\
\text { Tanda - } \\
\text { Tanda } \\
\text { keberadaan } \\
\text { Tikus dan } \\
\text { Keberadaan } \\
\text { Tikus }\end{array}$ & $\begin{array}{c}\text { Terdapat } \\
\text { Tanda - } \\
\text { Tanda } \\
\text { keberadaan } \\
\text { Tikus dan } \\
\text { Keberadaa } \\
\text { n Tikus }\end{array}$ & & \\
\hline & $\begin{array}{ll}\mathrm{n} & (\%)\end{array}$ & n $\quad(\%)$ & $(\%)$ & \\
\hline Baik & $28 \quad 96,6 \%$ & $0 \quad 0 \%$ & $100 \%$ & \multirow[b]{2}{*}{0,000} \\
\hline Tidak & $11,1 \%$ & $8 \quad 88,9 \%$ & $100 \%$ & \\
\hline Baik & \multicolumn{2}{|c|}{ Keberadaan Tikus di Kapal } & & \multirow[b]{2}{*}{$\begin{array}{l}\text { Nilai } \\
\mathrm{P}\end{array}$} \\
\hline \multirow[t]{2}{*}{$\begin{array}{c}\text { Sanitasi } \\
\text { Kapal }\end{array}$} & $\begin{array}{c}29 \text { Têdapô } \\
\text { Tanda - } \\
\text { Tanda } \\
\text { keberadaan } \\
\text { Tikus dan } \\
\text { Keberadaan } \\
\text { Tikus } \\
\end{array}$ & $\begin{array}{c}8 \text { fdrda } \\
\text { Tanda } \\
\text { keberadaan } \\
\text { Tikus dan } \\
\text { Keberadaa } \\
\text { n Tikus }\end{array}$ & 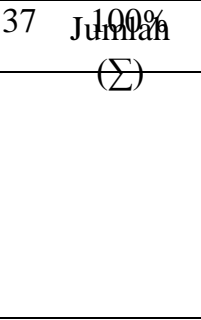 & \\
\hline & $\begin{array}{ll}\mathrm{n} & (\%)\end{array}$ & n $\quad(\%)$ & $(\%)$ & \multirow{3}{*}{0,000} \\
\hline $\begin{array}{l}\text { Memenu } \\
\text { hi Syarat }\end{array}$ & $\begin{array}{c}100,0 \\
\%\end{array}$ & $\begin{array}{ll}0 & 6,7 \%\end{array}$ & $\begin{array}{c}100,0 \\
\%\end{array}$ & \\
\hline $\begin{array}{l}\text { Tidak } \\
\text { Memenu } \\
\text { hi Syarat }\end{array}$ & $3 \quad 27,3 \%$ & $8 \quad 72,7 \%$ & $\begin{array}{c}100,0 \\
\%\end{array}$ & \\
\hline
\end{tabular}

\begin{tabular}{lllllll}
\hline Jumlah & 29 & $78,4 \%$ & 8 & $21,6 \%$ & 37 & $100,0 \%$
\end{tabular}

dengan sanitasi lingkungan dan kurangnya kepedulian anak buah kapal terhadap kebersihan di kapal terutama tempat - tempat yang dapat menjadi sumber makanan dan tempat perkembangbiakan tikus.

2. Analisis Bivariat

a. Hubungan Sanitasi Kapal dengan keberadaan Tikus

Pada kapal yang mempunyai sanitasi kapal memenuhi syarat dan tidak terdapat tanda - tanda keberadaan tikus maupun keberadaan tikus sebanyak 26 kapal , sedangkan pada kapal yang mempunyai sanitasi kapal tidak memenuhi syarat dan tidak terdapat tanda - tanda keberadaan tikus maupun keberadaan tikus sebanyak 3 kapal . Kapal yang memiliki tanda - tanda keberadaan tikus - dan keberadaan tikus dalam kategori tidak memenuhi syarat sebanyak 8 kapal.

Hasil analisis hubungan antara variabel sanitasi kapal dengan keberadaan tikus di kapal menggunakan uji chi square menunjukan hasil Fisher excact $\rho$ value $=$ 0,000 lebih kecil dari $\alpha$ : 0,05 maka dinyatakan Ho ditolak dan Ha sehingga dapat disimpulkan ada hubungan antara sanitasi kapal dengan keberadaan tikus..

a. Hubungan Perilaku Anak Buah Kapal dengan Keberadaan Tikus di Kapal

Perilaku anak buah kapal yang dalam kategori baik sebanyak 28 kapal, perilaku anak buah kapal dalam kategori baik tidak berpotensi untuk mengundang tanda - tanda keberadaan tikus dan keberadaan tikus,sedangkan pada kapal yang mempunyai perilaku anak buah kapal dalam kategori tidak baik sebanyak 9 kapal yang tidak terdapat tanda - tanda keberadaan tikus dan keberadaan tikus sebanyak 1 kapal dengan persentase 11,1 \% dan kapal yang terdapat tanda- tanda keberadaan tikus dan keberadaan tikus sebanyak 8 kapal dengan persentase 88,9 $\%$

Hasil analisis hubungan antara variabel perilaku anak buah kapal dengan keberadaan tikus di kapal menunjukkan hasil p value 0,00 lebih kecil dari $\alpha: 0,005$ maka dinyatakan ada hubungan antara perilaku anak buah kapal dengan keberadaan tikus di kapal.

\section{B. Pembahasan}

1. Sanitasi Kapal

Kapal yang memiliki kondisi sanitasi kapal yang memenuhi syarat sebanyak 26 kapal dengan persentase 70,3 \% dan kapal yang memiliki kondisi sanitasi yang tidak memenuhi syarat sebanyak 11 kapal dengan persentase 29,7 \% . Hal ini menunjukkan > $50 \%$ kapal yang diperiksa memiliki kondisi sanitasi kapal yang memenuhi syarat. akan tetapi, kapal yang telah memenuhi syarat tidak sepenuhnya bebas dari risiko di temukan tanda - tanda keberadaan tikus dan keberadaan tikus. Masih didapatkan ruang - 
ruang yang belum memenuhi persyaratan sanitasi kapal dan berpotensi mengundang tikus yang dapat menjadi sumber makanan dan tempat perkembangbiakan tikus.

Perbaikan sanitasi kapal sangat diperlukan kepada kapal yang tidak memenuhi persyaratan sanitasi kapal terutama pada ruangan yang berpotensi besar mengundang tikus seperti dapur, ruang rakit makanan dan gudang penyimpanan bahan makanan yang harus selalu di perhatikan kebersihan dan kerapihannya.

Perusahaan pemilik kapal sebaiknya meningkatkan peraturan beserta sanksi apabila melanggar tentang sanitasi kapal dalam pengawasan oleh kapten kapal kepada anak buah kapal maupun penumpang kapal sehingga kebersihan pada setiap ruangan dapat terjaga dengan baik.

Perbaikan sistem pelaksanaan sanitasi kapal untuk setiap anak buah kapal yang bertanggungjawab pada setiap ruangan untuk menjaga kebersihan ruangan dengan memperhatikan pengolahan sampah.

\section{Perilaku Anak Buah Kapal}

Kapal yang memiliki anak buah kapal berperilaku baik sebanyak 28 orang dengan persentase 75,6 \% dan anak buah kapal yang memiliki perilaku tidak baik sebanyak 9 orang dengan persentase 24,4 \%.Hal ini menunjukkan bahwa kapal yang memiliki anak buah kapal dengan perilaku baik > $50 \%$ kepada anak buah kapal yang telah di wawancara. Akan tetapi, perilaku anak buah kapal yang dalam kategori baik tidak sepenuhnya tidak berisiko mengundang keberadaan tikus dikarenakan masih banyak perilaku anak buah kapal yang kurang peduli dengan sanitasi lingkungan dan kurangnya kepedulian anak buah kapal terhadap kebersihan di kapal terutama tempat - tempat yang dapat menjadi sumber makanan dan tempat perkembangbiakan tikus.Keberadaan vektor penyakit dikapal selain disebabkan oleh faktor- faktor fisik di kapal yaitu ruangan/kompartemen kapal, juga tidak terlepas dari tindakan anak buah kapal (ABK), demikian juga setiap kapal yang bersandar, pada tali kapal tidak dipasang perisai tikus, penerangan pada ruangan/kompartemen kapal sering tidak menyala. Hal ini dapat menyebabkan berkembang biaknya vektor pada ruangan/ kompartemen kapal yang merupakan faktor risiko terjadinya sumber dan penularan penyakit.

Perusahaan pemilik kapal memberikan pengetahuan melalui penyuluhan tentang bahaya tikus di kapal , cara pengendaliannya dan hygiene perorangan dalam rangka meningkatkan kesadaran anak buah kapal. Kapten kapal sebaiknya membuat sanksi hukuman kepada anak buah kapal apabila melanggar sanitasi lingkungan. Memperhatikan perisai tikus (Rat Guard) pada tali tambat kapal yang menjad jalan masuknya tikus dari dermaga menuju kapal agar tetap terpasang sebagai upaya pencegahan.

3. Hubungan Sanitasi Kapal dengan Keberadaan Tikus

Pada kapal yang mempunyai sanitasi kapal memenuhi syarat dan tidak terdapat tanda - tanda keberadaan tikus maupun keberadaan tikus sebanyak 26 kapal, sedangkan pada kapal yang mempunyai sanitasi kapal tidak memenuhi syarat dan tidak terdapat tanda - tanda keberadaan tikus maupun keberadaan tikus sebanyak 3 kapal . Kapal yang memiliki tanda - tanda keberadaan tikus - dan keberadaan tikus dalam kategori tidak memenuhi syarat sebanyak 8 kapal. Tikus mampu menularkan penyakit pada manusia dengan membawa benih penyakit, pinjal, kutu, bakteri dan parasit. Binatang dari suku Murides ini dikenal sebagai sumber beberapa penyakit zoonosis. Beberapa jenis penyakit yang ditularkan oleh tikus antara lain Pes/Plaque, Leptospirosis, Scub Typhus, Murine Thypus, Rat Bite Fever, Salmonellosis, Lymphatic Chorionmeningitis, Hantavirus Pulmonary Syndrome dan Lassa Fever. Penyakit-penyakit tersebut ditularkan tikus melalui cara bervariasi mulai dari gigitan tikus, kencing tikus, kotoran tikus, maupun 
yang ditularkan secara tak langsung melalui hewan lain yang tertular penyakit dari tikus maupun makanan/minuman, air, atau benda yang terkontaminasi.

Hasil analisis hubungan antara variabel sanitasi kapal dengan keberadaan tikus di kapal menggunakan uji chi square menunjukan hasil $\mathrm{p}$ value 0,000 lebih kecil dari $\alpha: 0,05$ maka dinyatakan ada hubungan antara sanitasi kapal dengan keberadaan tikus. Kapal yang memiliki sanitasi kapal yang tidak memenuhi persyaratan dapat mengundang tikus dikarenakan limbah makanan berpotensi mengundang binatang penggangu (tikus) .(WHO,2008)

Hal ini disebabkan kondisi ruang - ruang pada kapal yang tidak memenuhi syarat kesehatan. Ruang yang paling banyak mempunyai faktor resiko untuk mengundang keberadaan tikus yaitu dapur yang tidak memenuhi syarat pada 20 kapal dengan persentasi 54,1 \%, Ruang rakit makanan pada 22 kapal dengan persentasi 40,5 \%, Palka pada 30 kapal dengan persentasi 81,1 \%, Limbah cair 26 kapal dengan persentasi 70,3\% sebagian besar kapal yang diteliti mempunyai dapur, ruang rakit makanan,palka,dan limbah cair yang tidak memenuhi persyaratan sanitasi kapal yang dapat berpotensi adanya risiko keberadaan tikus.

Menurut

penelitian (Nurcholis,1999) yang menyatakan dari hasil uji fisher exact didapatkan $\rho=0,023(\rho<\alpha)$ yang artinya terdapat hubungan bermakna antara sanitasi kapal dengan tanda- tanda kebradaan tikus dan keberadaan tikus pada kapal yang berbendera RI. Hal ini ditunjukkan adanya tanda keberadaan tikus pada kapal dengan kapal dengan sanitasi tidak memenuhi syarat sebanyak $43 \%$ dan tanda tanda keberadaan tikus pada kapal yang sanitasinya memenuhi syarat sebesar 4\%, terlihat bahwa dengan kondisi sanitasi kapal yang tidak memenuhi syarat maka tanda tanda keberadaan tikus lebih tinggi.

Penelitian ini mempunyai hasil yang sama dengan penelitian sebelumnya yang dilakukan oleh
(Nurcholis,1999), penelitian ini memiliki hasil hubungan antara sanitasi kapal dengan keberadaan tikus di kapal jumlah kapal yang memenuhi syarat adalah 25 kapal dengan persentase $78 \%$ sedang kapal dengan kondisi sanitasi tidak memenuhi syarat 7 Kapal dengan 22 \% dan tanda - tanda tikus yang ditemukan adalah kotoran,bekas jalan,dan tanda - tanda keberadaan tikus.

Pengawasan oleh pihak
Kantor Kesehatan Pelabuhan sebaiknya ditingkatkan agar pemilik perusahaan kapal lebih memperhatikan dan bertanggungjawab atas kapal miliknya sebagai alat angkut barang maupun penumpang yang terbebas dari faktor resiko penularan penyakit Sebagai aplikasi mencegah ancaman penyakit berbasis lingkungan di kapal sesuai dengan International Health regulation (IHR) tahun 2008.

4. Hubungan Perilaku Anak Buah Kapal dengan keberadaan Tikus

Perilaku anak buah kapal yang dalam kategori baik sebanyak 28 kapal, perilaku anak buah kapal dalam kategori baik tidak berpotensi untuk mengundang tanda - tanda keberadaan tikus dan keberadaan tikus,sedangkan pada kapal yang mempunyai perilaku anak buah kapal dalam kategori tidak baik sebanyak 9 kapal yang tidak terdapat tanda - tanda keberadaan tikus dan keberadaan tikus sebanyak 1 kapal dengan persentase 11,1 $\%$ dan kapal yang terdapat tanda- tanda keberadaan tikus dan keberadaan tikus sebanyak 8 kapal dengan persentase 88,9 $\%$.

Hasil analisis hubungan antara variabel perilaku anak buah kapal dengan keberadaan tikus di kapal menunjukkan hasil $\mathrm{p}$ value $=0,00$ lebih kecil dari $\alpha=0,05$ maka dinyatakan ada hubungan antara perilaku anak buah kapal dengan keberadaan tikus di kapal. Perilaku yang dapat mengundang keberadaan tikus dikapal sebagian besar pada perilaku memisah sampah bedasarkan jenisnya sebanyak 15 orang dengan persentase 40,5 \%, Membersihkan dapur menggunakan desinfektan sebanyak 17 orang 45,5 $\%$,membersihkan gudang 13 orang 35,1 \%hal ini menunjukkan bahwa perilaku 
anak buah kapal dapat mengundang keberadaan tikus. Dapur yang tidak di bersihkan menggunkan desinfektan membuat dapur tidak bersih secara sempurna, sisa makanan setelah masak disekitar dapur yang dapat menjadi sumber makanan dapat mengundang tikus. Gudang yang tidak pernah dibersihkan secara rutin juga berpotensi mengundang tikus dikarenakan gudang yang menjadi tempat persembunyian tikus terutama gudang bahan kering yang mempunyai suhu kamar yang akses masuk dan keluar tikus sangat ,mudah yang merambat melalui dinding.

Penelitian ini berbeda dengan penelitian sebelumnya yang mempunyai hasil tidak terdapat hubungan antara perilaku anak buah kapal dengan keberadaan tikus. Menurut penelitian yang dilakukan (ismail,2009) yang dilakukan menggunakan analisis uji regresi logistik ganda pada taraf kepercayaan $95 \%$ .hasil penelitian menunjukkan bahwa tidak ada hubungan perilaku anak buah kapal terhadap pengendalian vektor dan binatang pengganngu yaitu didapatkan $p=0,871(p>\alpha)$.

Perusahaan pemilik kapal bertanggungjawab penuh terhadap perilaku anak buah kapal dalam upaya kesehatan lingkungan di kapal. Pemilik perusahaan sebaiknya memberikan tugas kepada kapten kapal untuk melakukan pengawasan terhadap kinerja anak buah kapal untuk setiap harinya untuk pengendalian risiko lingkungan di kapal.

\section{Kesimpulan}

Bedasarkan pada hasil dan pembahasan dapat disimpulkan sebagai berikut :

1. Kapal yang terdapat tanda - tanda keberadaan tikus dan keberadaan tikus sebanyak 8 kapal dengan persentase 21,6 \% sedangkan, kapal yang tidak terdapat tikus sebanyak 29 kapal dengan persentase 78,4 \%.

2. Kapal yang memiliki sanitasi kapal memenuhi syarat sebanyak 26 kapal dengan persentase 70,3 \% sedangkan kapal yang tidak memenuhi syarat sebanyak 11 dengan 29,7 \%

3. Kapal yang memiliki perilaku anak buah kapal dalam kategori baik sebanyak 28 kapal dengan persentase sedangkan 75,5 \% kapal yang memiliki perilaku anak buah kapal dalam kategori tidak baik sebanyak 9 kapal dengan persentase $24,4 \%$.

Analisis hubungan sanitasi lingkungan dan perilaku anak buah kapal dengan keberadaan tikus pada kapal yang bersandar di wilayah kerja Kantor Kesehatan Pelabuhan Kelas I Surabaya Tahun 2017 :

1. Ada hubungan yang bermakna antara sanitasi kapal dengan keberadaan tikus pada kapal yang bersandar di wilayah kerja Kantor Kesehatan Pelabuhan Kelas I Surabaya Tahun 2017, karena nilai Fisher Exact $\rho=0,000(p>0,05)$

2. Ada hubungan yang bermakna antara perilaku anak buah kapal dengan keberadaan tikus pada kapal yang bersandar di wilayah kerja Kantor Kesehatan Pelabuhan Kelas I Surabaya Tahun 2017 karena nilai Fisher Exact $\rho=0,000$ $(\mathrm{p}>0,05)$

\section{Daftar Pustaka}

Bhisma Murti, 2010, Desain dan Ukuran Sampel Untuk Penelitian Kuantitatif dan Kualitatif di Bidang Kesehatan Edisi Kedua, Yogyakarta : Gadjah MadaUniversity Press

Chasan S Kusnadi, 2006, Pengendalian Vektor dan Binatang Pengganggu, Makasar: Instalasi Penerbitan Jurusan Kesehatan Lingkungan Politeknik Kesehatan Makasar
CDC,2003
,Guidelines
for enviromental infection control :WHO

Departemen Kesehatan R.I. Direktorat Jenderal Pemberantasan Penyakit MenularDan Penyehatan Lingkungan (DIT.JEN.PPM\&PL), 2002, PedomanPengendalian Tikus : Khusus Di Rumah Sakit, Jakarta : Depkes RI

Enceng Surachman \& Widada Suryanto, 2012, Hama Tanaman Pangan, Holtikultura, dan Perkebunan, Masalah dan Solusinya, Yogyakarta : Kanisius

Green,W,Lawrence .et.al,Health Education Planing A Diagnostik Approach,The Johns Hapkins University: Mayfield Company 
Halidya Mutiarani, 2009, Perancangan dan pengujian perangkap, pengujia jenis rodentisida dalam pengendalian tikus pohon (Rattus tiomanicus), tikus rumah (Rattus-rattus diardi), dan tikus sawah (Rattus argentiventer) di Laboratorium,skripsi, Bogor : Departemen Proteksi Tanaman, Fakultas Pertanian, InstitutPertanian Bogor

IHR,2005 , InternationalHealth Regulation , 2005 . Jakarta

Menkes RI ,2014 Permenkes RI No 82 Th 2014 Tentang Penanggulangan Penyakit menular

Menkes RI 2007 Pedoman Teknis penegndalian Resiko Kesehatan Lingkungan di Pelabuhan/Bandara/Pos Lintas batas Dalam Rangka Karantina Kesehatan

Menkes RI 1987 Peraturan Menteri Kesehatan No 530/MENKES/PER/VII/1987 Tentang Sanitasi kapal

Menkes RI 2015 , Peraturan Menteti Kesehatan No 40 Tahun 2015

Menkes RI 2003, Persyaratan Hygienen Sanitasi Jasaboga No 715 Tahun 2003

Notoatmodjo,Soekidjo,2003.Pendidikan Dan Perilaku Kesehatan : Rineka Cipta.Jakarta

Peraturan Menteri Kesehatan RI No.356/Menkes/Per/IV/2008 organisasi dan tata kerja kantor kesehatan pelabuhan

Peraturan Pemerintah Nomor 7 Tahun 2000 Tentang Kepelautan

Rusmini, 2011, Bahaya Leptospirosis (Penyakit Kencing Tikus) \& Cara Pencegahannya Edisi Pertama, Jakarta : Gosyen Publishing.

Sarwono ,sarlito W. Psikologi Sosial .salemba Humanika,jakarta 2004

Notoatmojo,Soekidjo,2007. Promosi Kesehatan dan Ilmu Perilaku. Rineka Cipta :Jakarta
Snedeecor GW \& Cochran WG, Statistical Methotds 6th ed Ames,IA: lowa State University Press,1967

Tri Cahyono, 2011, Pedoman Penulisan Proposal Penelitian dan Karya Tulis Ilmiah edisi revisi kedua, Purwokerto : Kementerian Kesehatan RI JurusanKesehatan Lingkungan Purwokerto

Untung Riyadi, 2012, Studi komparasi kesukaan tikus memakan umpan antara umpan rodentisida" $X$ " dan umpan kelapa bakar di perumahan tanjung elok kecamatan purwokerto selatan kabupaten banyumas tahun 2012, karya tulis ilmiah, Purwokerto : Kementerian Kesehatan RI Politeknik Kesehatan Kemenkes Semarang Jurusan Kesehatan Lingkungan Purwokerto

KKP Surabaya,2015 Buku Laporan Tahunan KKP Kelas I Surabaya : Surabaya

WHO,2011, Guide To Ship Sanitation Third Edition :Geneva. 